\title{
A Rock Fracturing Method Using High-Pressure Gas Expansion: Case Study on Its Application in Hangzhou-Lin'an Intercity Railway
}

\author{
Dunwen Liu, Yu Tang $(D$, Caiwu Cai, and Yinghua Jian \\ School of Resources and Safety Engineering, Central South University, Changsha 410083, China \\ Correspondence should be addressed to Yu Tang; tangyu9433@163.com
}

Received 1 November 2020; Revised 25 April 2021; Accepted 27 April 2021; Published 6 May 2021

Academic Editor: Jian Ji

Copyright (c) 2021 Dunwen Liu et al. This is an open access article distributed under the Creative Commons Attribution License, which permits unrestricted use, distribution, and reproduction in any medium, provided the original work is properly cited.

\begin{abstract}
The use of explosives in cities is under strict control due to the risks associated with blasting. It is difficult to perform nonexplosive continuous excavation on hard rock connecting passage in crowded cities with dense high buildings and populations safely and rapidly. Therefore, a new method of rock fracturing through high-pressure gas expansion is proposed. The method was applied for the excavation of a connecting passage on the Hangzhou-Lin'an Intercity Railway in China. Analysis was conducted on the parameters of rock fracturing, rock fracturing effects of this method, and its impact on the vibration of surrounding buildings. Overall, when the compressive strength of rock reaches $100 \mathrm{MPa}$, and the surrounding rocks are dense, this method of rock fracturing can fully meet the requirements of rapid excavation in a connecting passage, and the vibration resulting from rock fracturing causes only a slight disturbance to the adjacent buildings. After optimizing the rock fracturing parameters, better, smoother rock fracturing effects are obtained, and a set of safe and efficient solutions to the excavation of hard rock in cities are created. It can provide a new approach for rock fracturing in similar projects.
\end{abstract}

\section{Introduction}

Due to the rapid development of urban construction and intensive land use in China, urban underground space has been fully developed and utilized. Urban subway construction has been the rapidest development in urban underground space and uses the majority of subsurface resources within cities. By September 2019, the total mileage of urban rails in China reached $6333 \mathrm{~km}$. With the construction of urban subways and the increased density of subway line network, the construction of urban underground tunnels will inevitably pass through hard strata. Tunnel Boring Machine (TBM) and shield method are usually applied in the main tunnels of an urban subway with hard rock strata, but there are some limitations in their size when excavating the subway connecting passage [1-3]. Mining method is often used in excavating the connecting passage of an urban subway, but the construction process with the mining method impacts the environment and safety near the blasting region. Safety regulations for blasting in
China strictly regulate the permissible value for blasting vibration safety, and the minimum allowable vibration speed of special buildings is only $0.1 \mathrm{~cm} / \mathrm{s}$ [4]. Furthermore, the mining method is considerably restricted in the construction of urban tunnels. Therefore, there is an urgent need for a new technique of rock fracturing suitable for rapid excavation of hard rock tunnels in cities. It should meet the requirements of limited space of connecting passage and ensure quick and safe excavation of tunnels with low disturbance to the surface and adjacent buildings.

Scholars have performed research on the construction of hard rock tunnels, and the research on excavation with low vibration mainly focused on optimizing blasting technology and nonexplosive excavation. Because urban subway excavation in China is sensitive to explosives, nonexplosive methods have mainly been adopted in research on the construction of urban subway with low disturbance. Apart from shield method and TBM, they mainly include mechanical milling method, the static expanding agent method, splitting bar method, the method of rock fracturing through 
pickaxe machine, and pneumatic picks [5-10]. Rock fracturing technology using high energy gas is mainly used for oil and gas field stimulation. The principle is to use a large amount of high-temperature and high-pressure gas produced by rapid combustion of gunpowder or rocket propellant in the wellbore to induce fractures within the surrounding rock [11-14]. However, the procedures for examination and approval of the application of gunpowder in cities are cumbersome, limiting the application of this method in urban hard rock regions. Rather than using gun powder, phase transformation of liquid carbon dioxide causes high pressure in due to the rapid volume expansion in the case of endothermic gasification of liquid carbon dioxide, fracturing the rock mass. The peak pressure for rock fracturing through this method is only $300 \mathrm{MPa}$, which fails to produce adequate rock fracturing within hard rock $[15,16]$. Currently, this method is mainly applied for blasting excavation of loose coal seams and medium hard rock with joint and fissure development [17-19]. Overall, nonexplosive excavation methods have the advantages of low vibration, low noise, and safety; however, they have a high cost and low efficiency in rock fracturing, need large amounts of personnel and equipment, and require multiple free faces. Especially, for the excavation of hard rock with the strength of over $50 \mathrm{MPa}$, they are extremely ineffective or even impossible to implement.

In order to solve the above problems, Liu's group of Central South University started to study the rock fracturing method by the gas production agent of automobile airbag in 2015, China. The concept of "high-pressure gas expansion rock fracturing technology" was first proposed. Based on this method, a rock fracturing product, expansion pipe, was produced by cooperating with enterprises. In 2016, the field test was carried out in a tunnel in Zhejiang Province, China. The tunnel passes through the water transfer tunnel (the minimum distance is $8.26 \mathrm{~m}$ ), and the maximum surrounding rock strength reaches $114.0 \mathrm{MPa}$. The field test results show that the high-pressure gas expansion rock fracturing technology is suitable for the excavation of hard rock tunnel adjacent to important buildings and structures, without major hazards of blasting vibration, noise, and flying rock. Then, the relevant basic theoretical tests are carried out in the tunnel [20]. The method solves the problem of surface vibrations caused by drilling and blasting during the construction of a tunnel and preliminarily proposes spacing pattern parameters of rock fracturing in a tunnel. However, the method has not been used in continuous and rapid excavation of hard rock connecting passage.

In this paper, based on the rock fracturing technology by high-pressure gas expansion, a study is conducted on the application of rock fracturing method through high-pressure gas expansion in a hard rock connecting passage of intercity railways in Hangzhou. Through continuous excavation of a connecting passage, the effect of high-pressure gas expansion in rock fracturing is verified, obtaining the parameters of rock fracturing and vibration at the surface. This paper is the first time to elaborate the method in international journals, hoping to provide reference for the application of this technology in hard rock tunnels in cities.

\section{Field Test}

2.1. Description of the Fieldwork. The section of the intercity railway from the Lin'an Square Station to the Agriculture and Forestry University Station scheduled to be built is mainly located under urban district with a total length of 3,790 m.

In Figure 1, the proposed tunnel passes through the urban district underground, and its adjacent buildings include a nursing home, colleges and universities, and highrise buildings. The high-rise buildings on the west side are at least about $27 \mathrm{~m}$ away from the tunnel. It is highly risky to use mining method in tunnel construction, so the mining method is limited during construction. Shield method will be used in the construction of the main lines. Six connecting passages are set up in this section. Among them, the surrounding rock of the connecting passage at DK8 +300 on the right of the mileage is a relatively competent, moderately weathered tuff (see Figure 2). It is classified as a Grade-III surrounding rock, which has better self-stabilization capacity.

The connecting passage has a total length of $9.34 \mathrm{~m}$, with the main tunnel $3.4 \mathrm{~m}$ in both height and width. With a smaller construction clearance, it is impossible to use a main tunnel shield machine in excavation. The adjacent construction is close to the excavation area, and there are many people and vehicles on the ground. Traditional mining method will cause public nuisances such as vibration, noise, and slungshot of debris, which has wide range of influence. Therefore, nonexplosive excavation is proposed for the project in this paper.

2.2. Rock Mechanics Parameters. The connecting passage consists of hard and dense rock, and it is necessary to the test rock mechanics parameters.

Rock samples were taken from the dense rock layer with good integrity and homogeneity on the tunnel face of the connecting passage. The rough base of the rock samples was shaped into a cylinder sample of $\Phi 50 \mathrm{~mm} \times 100 \mathrm{~mm}$ by drilling (see Figure 3), cutting, and polishing, making the parallelism and nonperpendicularity of the end face less than $0.02 \mathrm{~mm}$ [21]. There were three test specimens in a group, and the mechanics performance testing was conducted using the MTS 322 hydraulic servo testing machine.

The stress-strain curve of tuff specimen is obtained through the test (see Figure 4). The maximum compressive strength of the rock obtained through testing is $101.4 \mathrm{MPa}$. Table 1 lists the mechanics parameters for the rock under a static load through the analysis of its stress-strain curve.

\subsection{Comparison and Selection of Construction Schemes}

2.3.1. Existing Nonexplosive Rock Fracturing Methods. To avoid the influence of adjacent buildings caused in construction of mining method, at the early stage of the project, a variety of nonexplosive excavation methods were tried. They included the crushing through static cracking agent, 


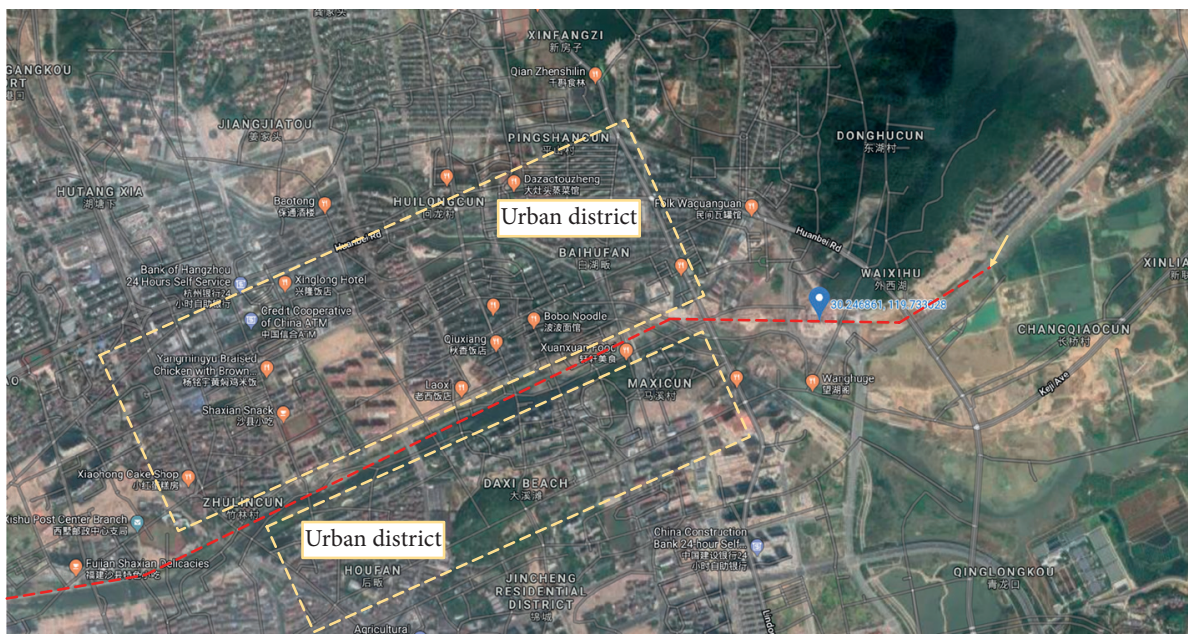

- - Proposed subway tunnel

Figure 1: Topographic map.

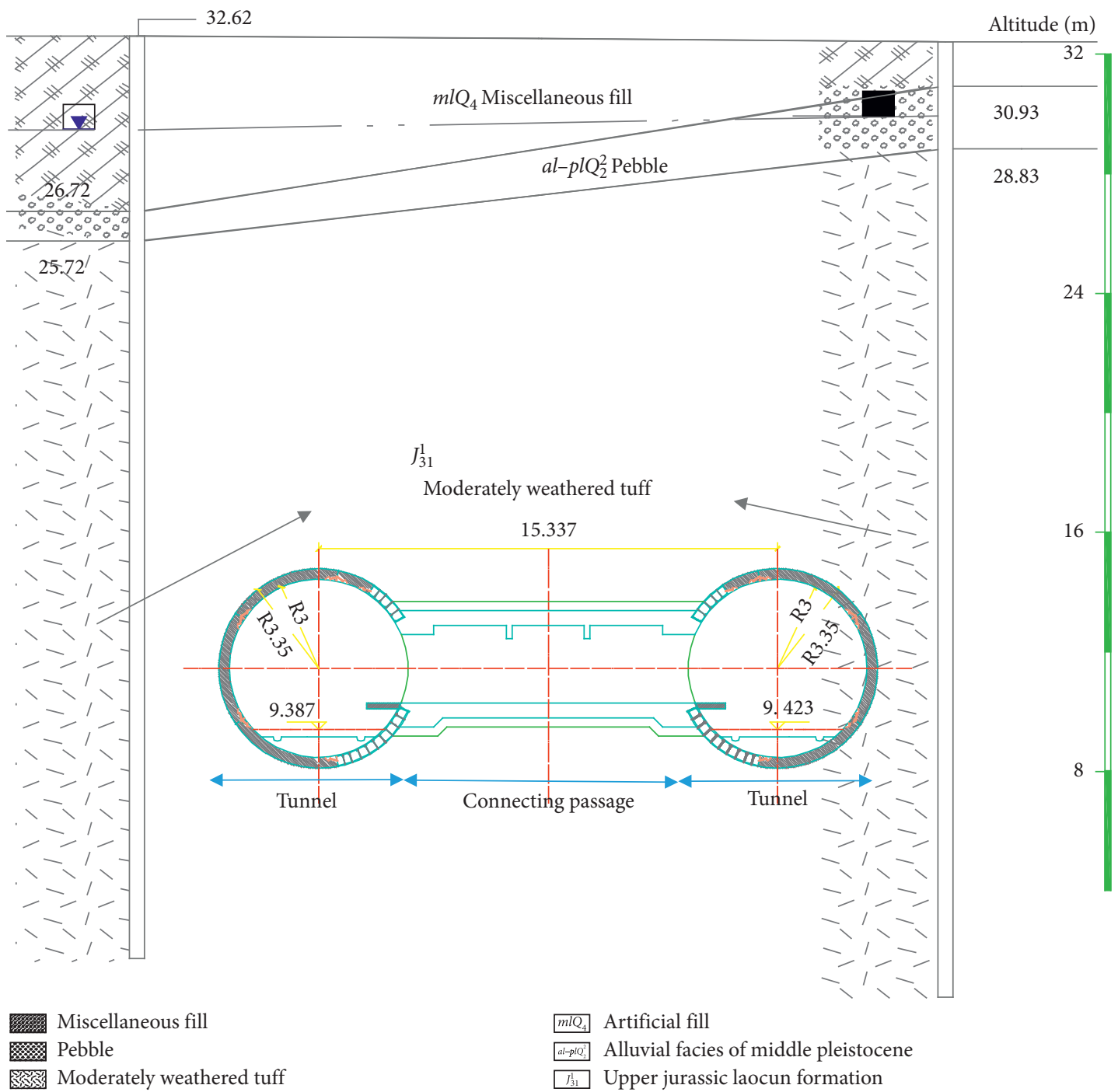

FIGURE 2: Geological histogram of the surrounding rock. 


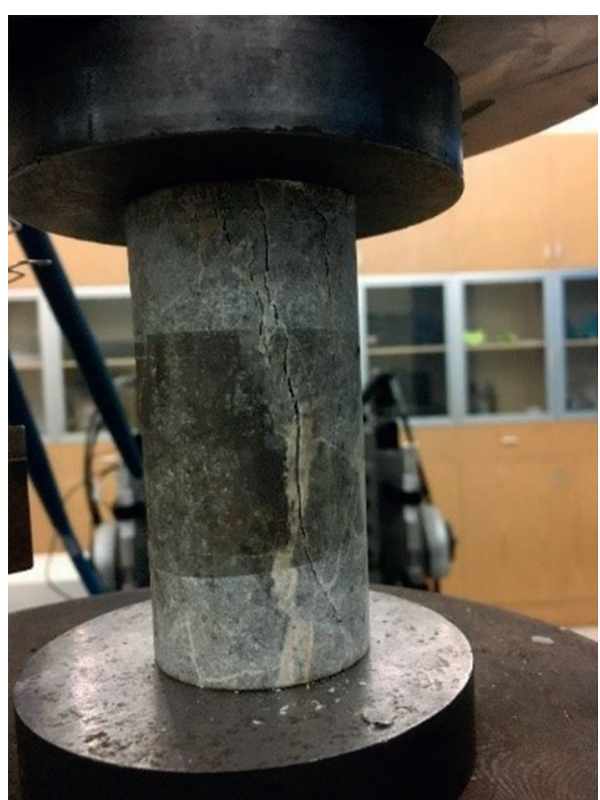

(a)

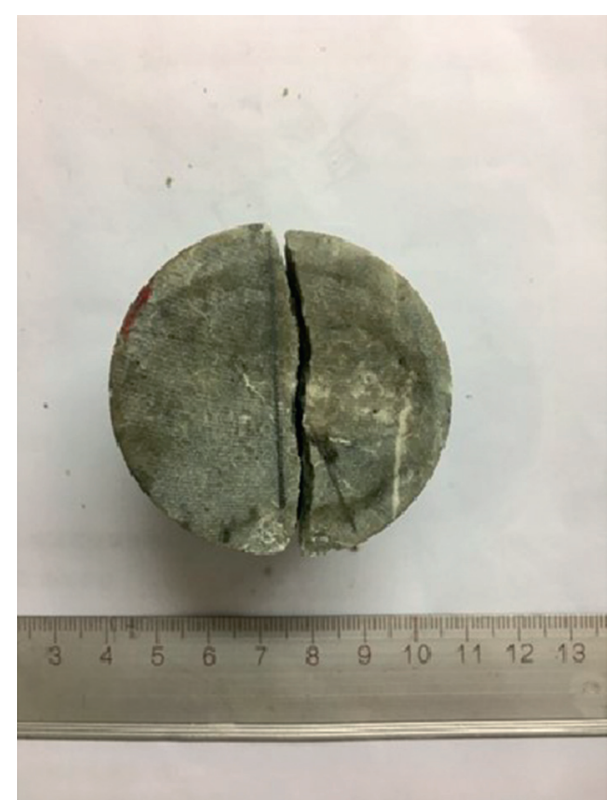

(b)

Figure 3: Failure mode of rock under static load test. (a) Front view; (b) top view.

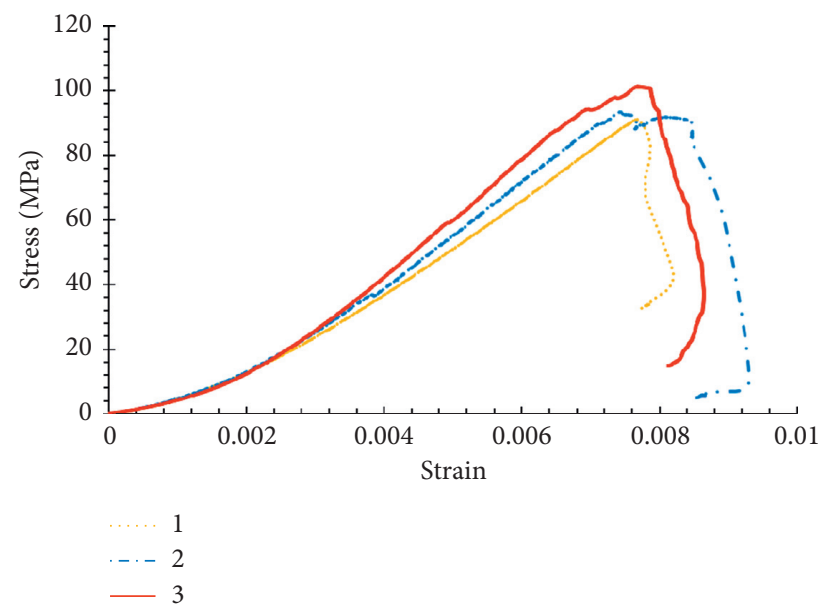

FIgURE 4: Stress-strain curve.

TABLE 1: Rock mechanics parameters.

Density $\left(\mathrm{kg} \cdot \mathrm{m}^{-3}\right)$ Average compressive strength $(\mathrm{MPa})$ Average tensile strength (MPa) Modulus of elasticity (GPa) Poisson's ratio 2688 95.92 3.95 14.50 0.24

mechanical fracturing with a hydraulic hammer, cutting with a wire saw, and water grinding drill.

Figure 5 shows the rock fracturing effect of three different nonblasting methods. Three cutting surfaces were cut at the entrance of the connecting passage using the cutting method with wire saw (see red arrows in Figure 5), but it failed to achieve ideal results. Due to the dense rock, the cutting surfaces were not conducive to further excavation by machinery. The crushing method using static cracking agent was tried at many locations at the entrance (see red arrows in Figure 5), but no significant cracks appeared within the rock, and no further excavation could be conducted. Finally, an approximate cylinder pilot tunnel with a diameter of $1 \mathrm{~m}$ was chiseled in the center of the step on the cross section of the connecting passage using a water grinding drill, which took three months, and many rock fracturing machines and tools were damaged in the process.

The nonexplosive excavation methods above produced slight vibrations at the surface; yet, they are costly, have low rock fracturing efficiency, and require large amounts of personnel and equipment. To accelerate excavation, save construction costs, and ensure completion on schedule, a 


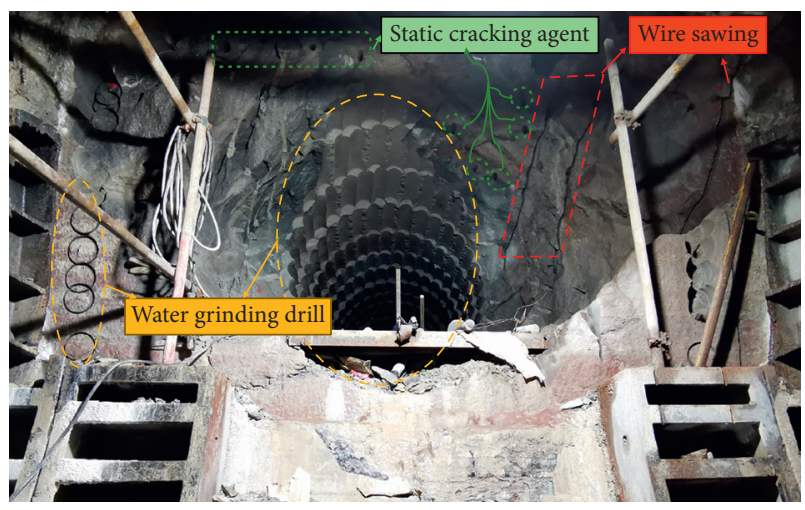

FIGURE 5: Rock fracturing effect of different excavation methods.

new rock fracturing method by high-pressure gas expansion was used in the continuous excavation of connection passage.

\subsubsection{The Rock Fracturing Method by High-Pressure Gas} Expansion. The rock fracturing method by high-pressure gas expansion fractures the rock using an aerogenic agent to release a large volume of high-temperature and high-pressure gas in a short time under a closed condition. It is similar to high-pressure gas detonation products and creates an "air wedge" effect consisting of a stress wave and high-pressure gas that act together on the rock mass. The device for rock fracturing by high-pressure gas expansion adopted in this excavation work is composed of an aerogenic agent, storage tube for the aerogenic agent, inflatable iron pipe, wire, highpressure air pump, and an electric trigger.

In Figure 6, the aerogenic agent is an effective part for rock fracturing using the expansion pipe; the inflatable iron pipe is used to connect to the air pump to allow for air conduction and compression. The storage tube for the aerogenic agent is made of a cylindrical PVC pipe with a diameter of $5 \mathrm{~cm}$, a length of $40 \mathrm{~cm}$, and a thickness of $2 \mathrm{~mm}$, in which $500 \mathrm{~g}$ of aerogenic agent is contained within. The aerogenic agent and storage tube are referred to as expansion tube hereinafter.

Rock fracturing using high-pressure gas expansion is performed systematically according to the surrounding rock conditions of the tunnel face, and the process of rock fracturing is shown in Figure 7.

Figure 7 lists the main process of rock fracturing; if there is no free face on the tunnel face for preliminary rock fracturing, it is necessary to perform underholing first. At the center of tunnel face, a water drilling machine was used to drill several holes with a large diameter and depth of $1.5 \mathrm{~m}$ perpendicular to the tunnel face from top to bottom. The hole diameter was adjusted according to the water drilling machine on the site, although not less than $10 \mathrm{~cm}$. The holes were mutually connected to form a grooving of $1.5 \mathrm{~m}$, creating a free surface and compensation space for rock fracturing.

Surveying and positioning were then conducted, and rock-fracturing holes were drilled. Besides, an expansion tube was set into the holes, and a quick setting, high density, and high strength hole plugging sizing agent was used to consolidate the expansion tube in the blast hole in a compact manner. While drilling holes, on the left and right sides of the grooving, a rock drill was used to drill two horizontal rock-fracturing holes with a diameter of $70 \mathrm{~mm}$, and a depth of $1.5 \mathrm{~m}$. They were perpendicular to tunnel surface from top to bottom. Generally, the parameters for hole spacing and minimum resistance line of upper and lower rock-fracturing holes should be adjusted according to rock strength.

Lastly, 2.5 MPa air was injected into the expansion tube through the inflatable iron pipe, and the multiple expansion tubes for one operation were connected in series by wires. An electric trigger activated the rock fracturing. After rock fracturing, the profile of excavation section was reconditioned by machinery, and then, the fallen rock was transported out. After the initial rock fracturing and underholing, rock-fracturing holes were arranged around the cutting according to the surrounding rock conditions.

If the tunnel surface has free faces for rock fracturing, rock-fracturing holes can be arranged around the existing free faces to perform rock fracturing in a cyclic manner. In the process of excavating the connecting passages in this paper, a water mill was used to excavate a cylindrical pilot hole with a diameter of $1 \mathrm{~m}$ on the tunnel surface, creating adequate free faces for rock fracturing. Therefore, it was unnecessary to perform underholing for the first rock fracturing.

\subsection{Test Scheme}

2.4.1. Experimental Analysis on Parameters of Rock Fracturing. The existing rock fracturing methods complicated surrounding rock conditions at the entrance of the connecting passage, such as underexcavation, overexcavation, and penetrating cracks (see Figure 5). These disadvantageous factors make the connecting passage contour irregular and affect the design of rock fracturing parameters in the entrance. Furthermore, the surrounding rock of this connecting passage has high strength and high density. The rock fracturing method by high-pressure gas expansion has not been applied under the conditions with the compressive strength of the rock over $100 \mathrm{MPa}$. Therefore, parameters of rock fracturing need to be determined.

In order to solve the problem of rock fracturing at the entrance and obtain parameters, we used six expansion pipes to test the effect of rock fracturing for the first time, and three expansion pipes were set on the vault and side wall, respectively.

In Figure 8, three rock fracturing holes (No. T1-T3) were arranged at the vault of the existing hole excavated by the water mill. According to the measured external contour of surrounding rock, the minimum resistance line $W$ was calculated to be about $0.45 \mathrm{~m}$, and the hole spacing was $0.35 \mathrm{~m}$. There were adjustments in the field drilling to avoid the penetrating holes at the early stage of construction. The measured hole spacing was $0.30 \mathrm{~m}$, and the hole depth was $1.5 \mathrm{~m}$. Because the integrity of the rock mass at the bottom of the fracturing hole could not 


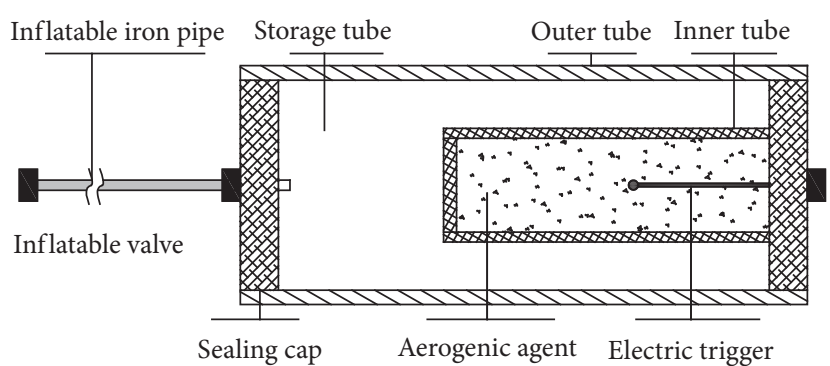

(a)

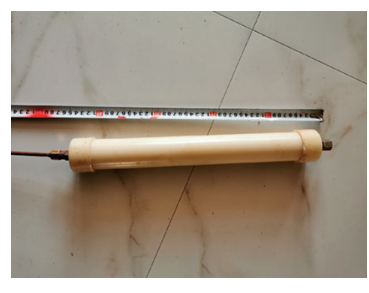

(b)

Figure 6: Expansion pipe. (a) Structure schematic drawing. (b) Product picture.

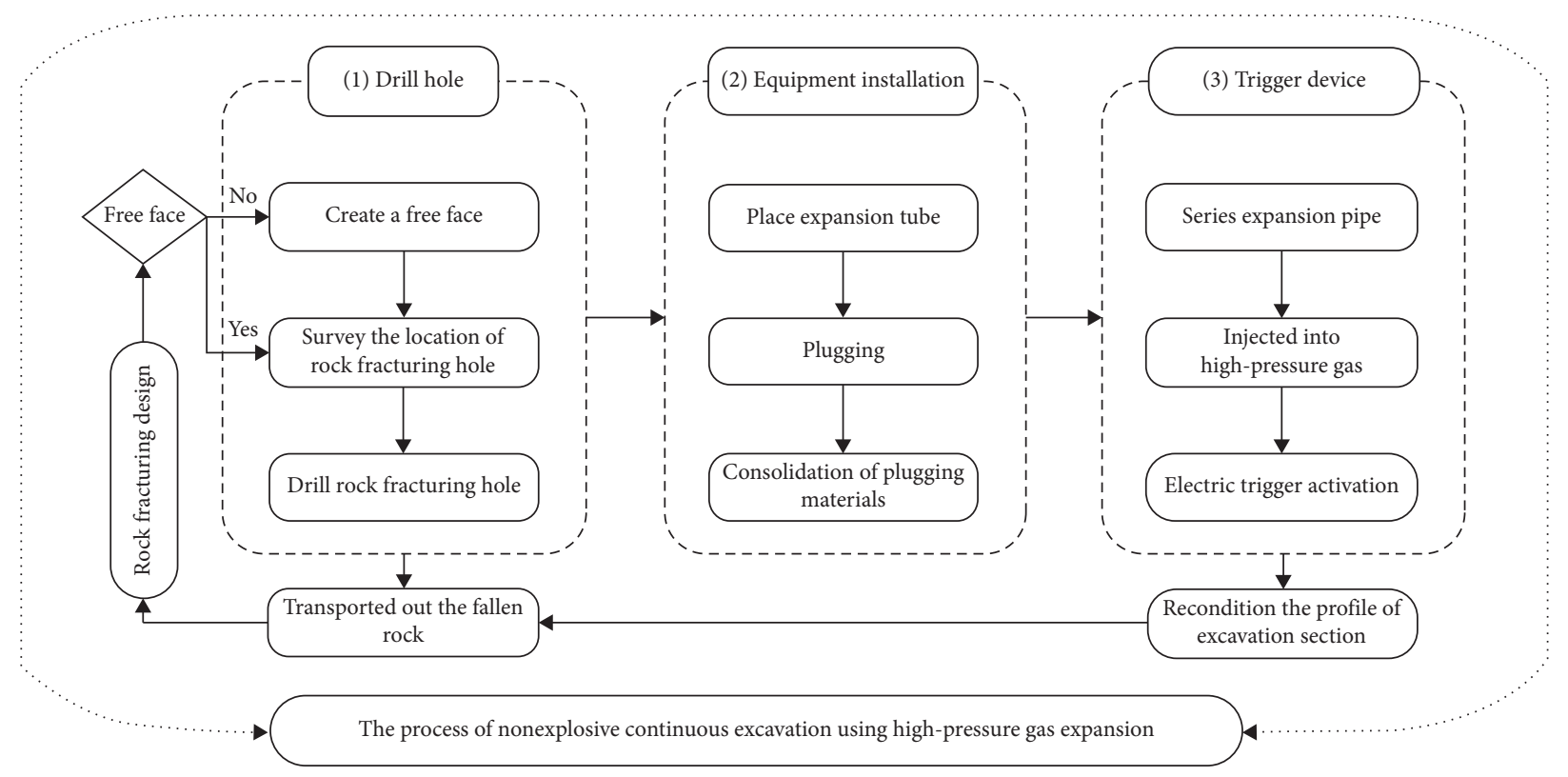

Figure 7: Rock fracturing process.

be determined, the expansion tube should not be directly put into the bottom of the hole. After the plugging material (about $0.3 \mathrm{~m}$ of the hole length) is injected into the bottom of the hole, the expansion tube was put into the hole, and then the rock fracturing holes were completely blocked using rapid hardening cement.

Figure 9 shows the initial rock fracturing effect of vault. In the three rock fracturing points of the vault, there were two complete half-hole marks on $\mathrm{T} 1$ and $\mathrm{T} 2$. As the whole rock mass at T3 falls, there was no obvious half-hole mark. The measured half-hole spacing was $0.3 \mathrm{~m}$, being completely consistent with the position of the drill holes. This indicated that there was no deviation among the drill holes. The halfhole length was $1.15 \mathrm{~m}$, which was basically the same as the length of expansion tube in the hole of $1.2 \mathrm{~m}$. According to the above results, it can be determined that the rock fracturing holes spacing is $0.3 \mathrm{~m}$, and the minimum resistance line is $0.45 \mathrm{~m}$.

In the initial rock fracturing test of the side wall, three rock fracturing holes were arranged (No. S1-S3), and the diameter and depth of each hole were the same as those of the vault. The design hole spacing was $0.55 \mathrm{~m}$ and $0.4 \mathrm{~m}$, respectively, and the minimum resistance line was $0.6 \mathrm{~m}$. In
Figure 9, three complete half-hole marks can be seen, indicating that a well smooth rock fracturing effect has been achieved. The measured hole spacing was $0.53 \mathrm{~m}$ and $0.36 \mathrm{~m}$, respectively, which was basically consistent with the design hole spacing (see Figure 10).

2.4.2. Rock Fracturing Test Scheme. In Section 2.4.1, we can conclude that the proposed method can successfully break hard rock under the conditions of the hole spacing of $0.55 \mathrm{~m}$, hole depth of $1.5 \mathrm{~m}$, hole diameter of $0.07 \mathrm{~m}$, and minimum resistance line of $0.6 \mathrm{~m}$. To optimize the parameters, achieve better smooth rock fracturing effect, and improve rock fracturing efficiency. In this section, several rounds of rock fracturing tests were carried out under the conditions of constant hole depth and diameter, hole spacing in the range of $0.5 \mathrm{~m}-1 \mathrm{~m}$, and minimum resistance line in the range of $0.6 \mathrm{~m}-0.8 \mathrm{~m}$.

According to multiple rock fracturing results, when the maximum hole spacing reached $1 \mathrm{~m}$, and the minimum resistance line was $0.8 \mathrm{~m}$, better rock fracturing effects were still achieved. However, when the hole spacing reached $0.6 \mathrm{~m}$, smooth rock fracturing effects were poor, with 


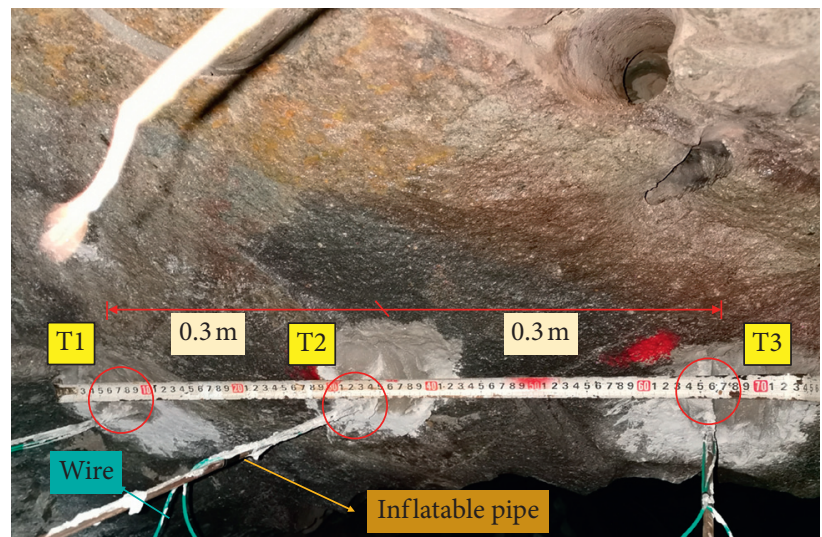

(a)

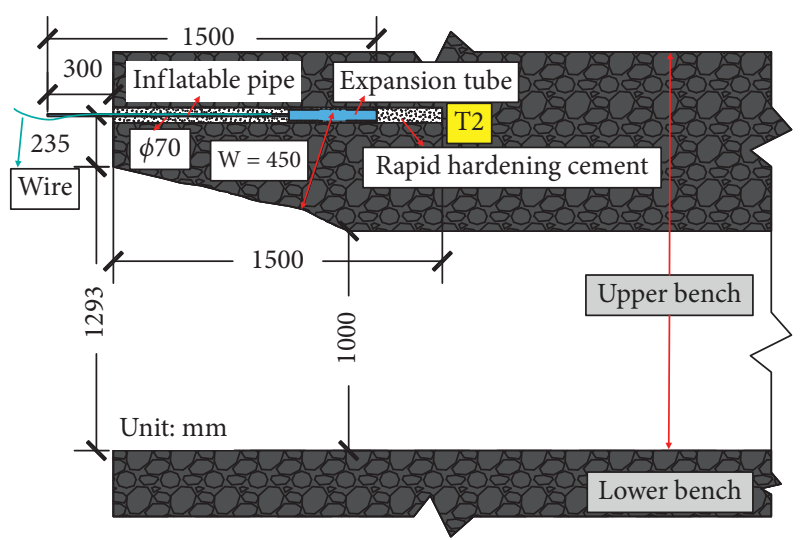

(b)

Figure 8: Arrangement of rock fracturing points on vault. (a) Actual arrangement; (b) profile.

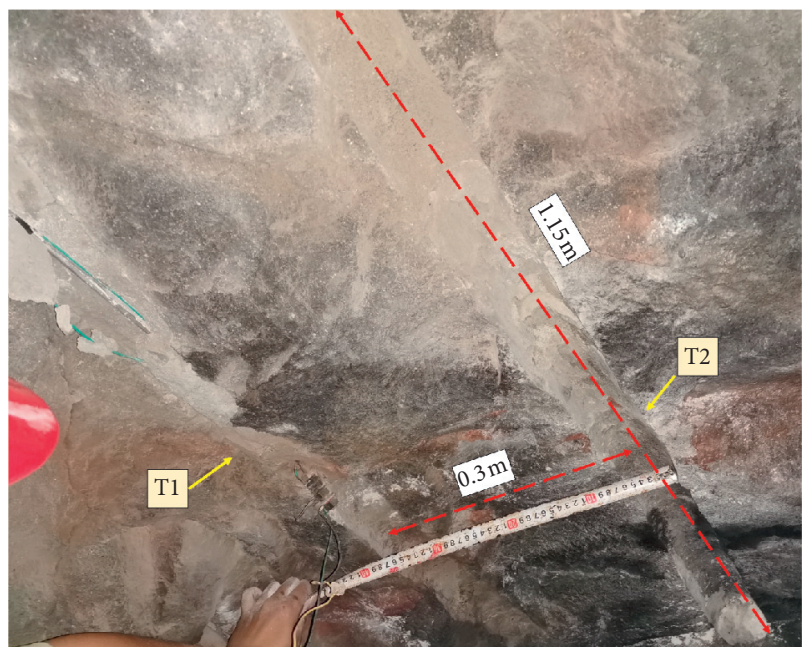

FIGURE 9: Initial rock fracturing effect on vault.

underexcavation occurring (see blue wireframe in Figure 11). When the hole spacing was $0.5 \mathrm{~m}$, the wall after rock fracturing was the smoothest, and the smooth rock fracturing effect was the best (see yellow wireframe in Figure 11). Therefore, in order to ensure the smooth fracturing rock effect, the peripheral holes should be arranged more densely, and the hole spacing should not exceed $0.5 \mathrm{~m}$. The distance between other holes should be within the range of $0.5 \mathrm{~m}-1 \mathrm{~m}$. To guarantee that the contour of the connecting passage was complete, and the excavation efficiency requirement of the project was satisfied, excavation of the cross section of the connecting passage was divided into 8 steps. The rock fracturing location and excavation process are shown in Figure 12.

In Figure 12, the excavation process was divided into eight steps involving the upper and lower steps. The excavation at upper step was conducted first. The maximum number of expansion tubes was eight, and the minimum number was four in a single operation of rock fracturing. The minimum resistance line and hole spacing were in the ranges of $0.3-0.7 \mathrm{~m}$ and $0.3-0.6 \mathrm{~m}$, respectively. To ensure smooth rock fracturing effects, the peripheral hole spacing was set to less than $0.5 \mathrm{~m}$

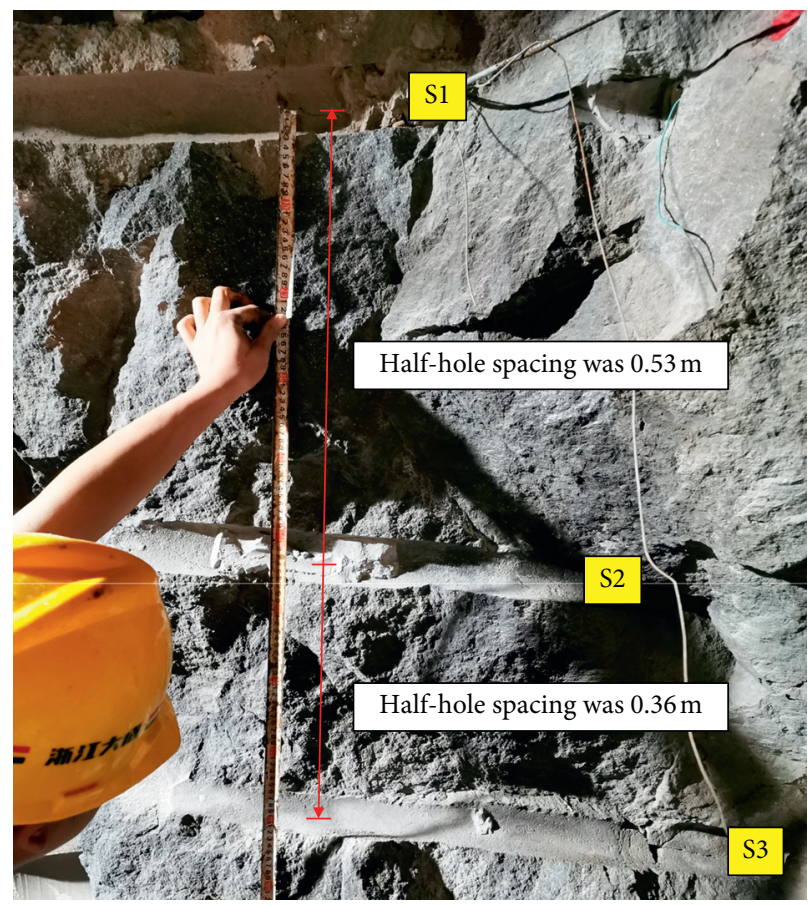

FIGURE 10: Initial rock fracturing effect on side wall.

2.4.3. Vibration Monitoring Scheme. In order to test the vibrational response of the surrounding buildings in the process of rock fracturing through high-pressure gas expansion in a hard rock subway tunnel, vibration monitoring points were arranged in the tunnel and on the ground, respectively. The location of vibration monitoring points is shown in Figure 13.

In the tunnel, two monitoring points were arranged on the right shield tunnel segments $9.5 \mathrm{~m}$ and $18.5 \mathrm{~m}$ away from the vibration center, which are numbered as $\mathrm{K} 1$ and $\mathrm{K} 2$ and located at the same horizontal line as the vibration center. On the ground, measuring point G1 was arranged on the road $30.11 \mathrm{~m}$ above the connecting passage, and G2 on the building steps closest to the vibration source (see Figure 13). 


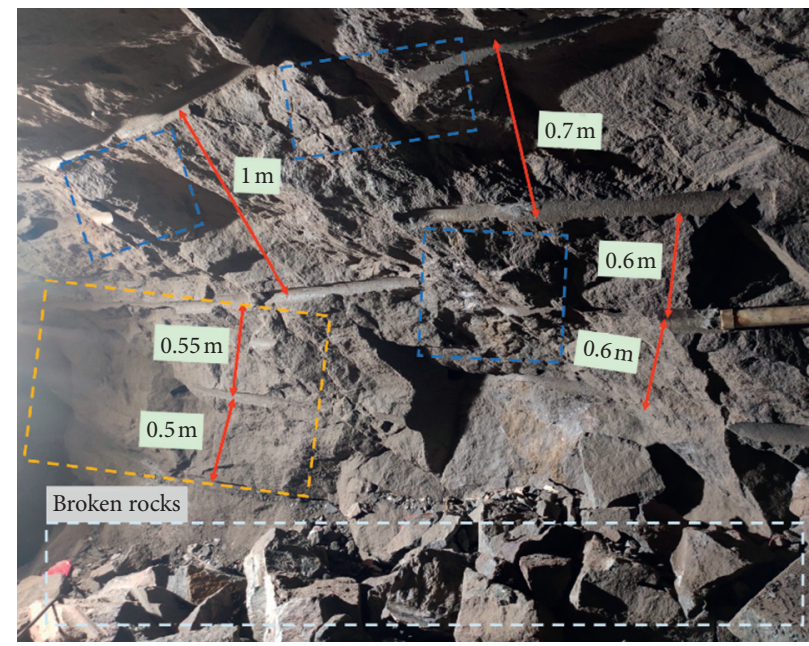

FIGURE 11: Effect of multiple rock fracturing.

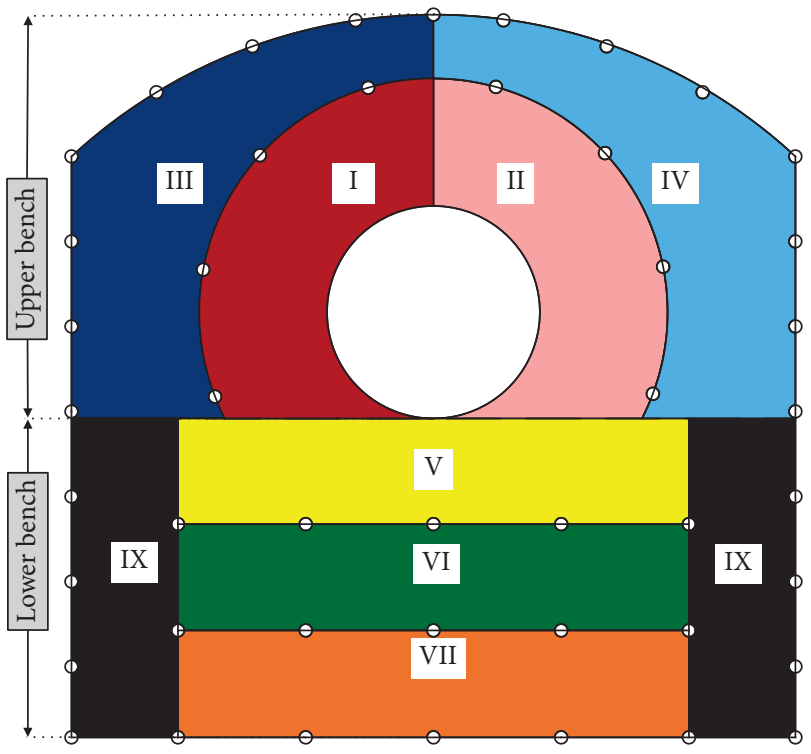

(a)

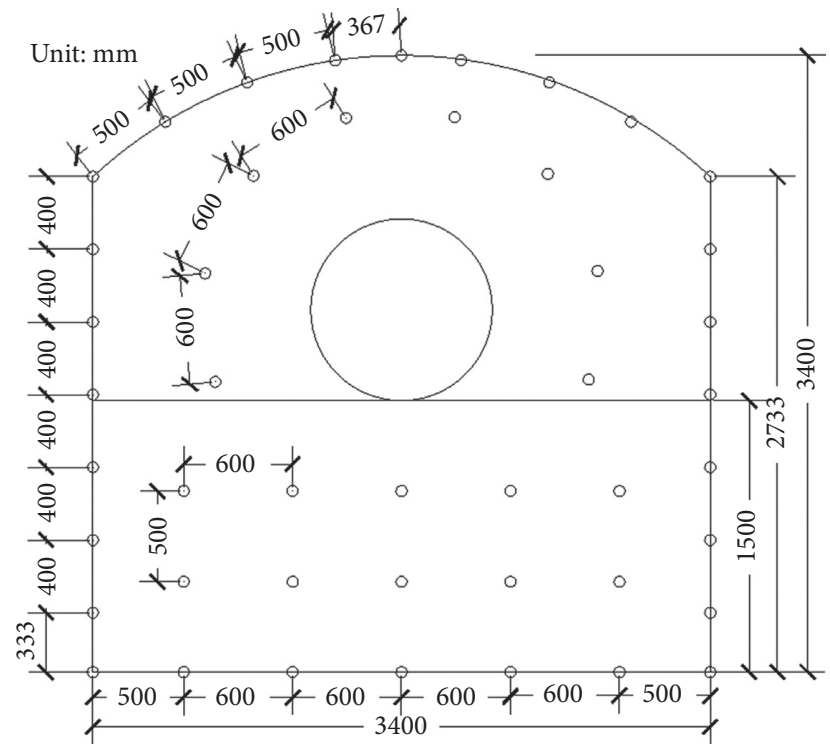

(b)

FIGURE 12: Rock fracturing scheme. (a) Excavation process. (b) Layout of rock fracturing hole.

\section{Results and Analysis}

3.1. Analysis of Rock Fracturing Effect. In terms of rock fracturing scheme and the requirements of the excavation sequence in rock fracturing test, continuous excavation was executed on the connecting passage. It achieved suitable smooth rock fracturing effects, as shown in Figure 14.

The contour of the connecting passage was smooth, and multiple residual half-hole marks are clearly visible on the vault (see Figure 14), with the rate of half-hole marks over $85 \%$. Except for some slight structural joints, no obvious cracks were noted on the wall surface. This indicates that rock fracturing through high-pressure gas expansion causes less damage to the remaining rock mass, guaranteeing the stability of the surrounding rock after excavation. The heights of the steps at the joint of adjacent excavation sections in the rock fracturing were within $15 \mathrm{~cm}$ at all times. No significant overexcavation and underexcavation occurred. The lumpiness of the rock debris falling in rock fracturing was well controlled, allowing for easy taking out the stones.

In Figure 15, the original structural surface of the failure surface of the rock debris was essentially retained, and the failure surface is relatively smooth. This indicates that the stress wave caused by rock fracturing by high-pressure gas expansion was not strong enough to smash the rock. It only caused small secondary fractures in the rock. Then, by virtue of the "air wedge" effect of high-pressure gas, fractures propagated in an instable manner first along the direction of maximum stress, initial fissures, joints, and other weak structural surfaces in rock mass. Finally, the fractures are connected with the free face to cause the rock to suffer spalling and exfoliation. 


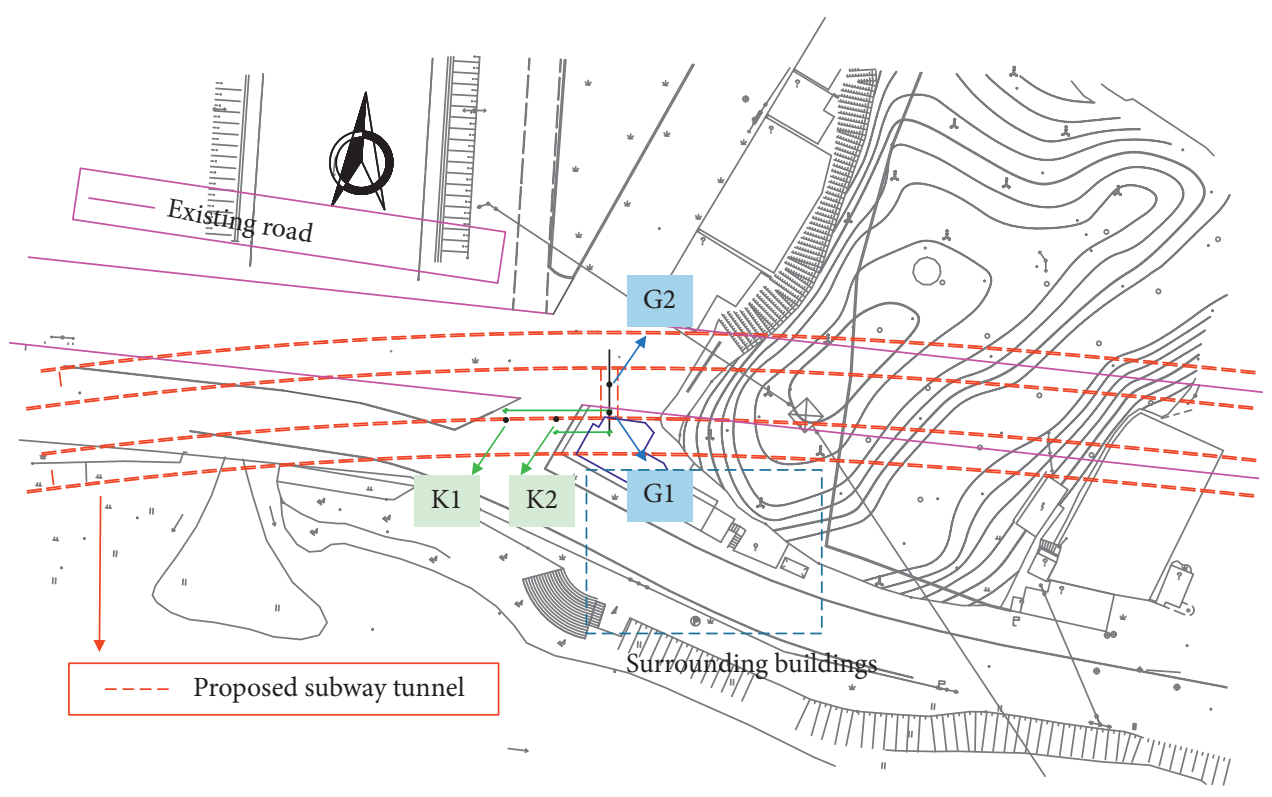

FIgURE 13: Arrangement of vibration monitoring points.

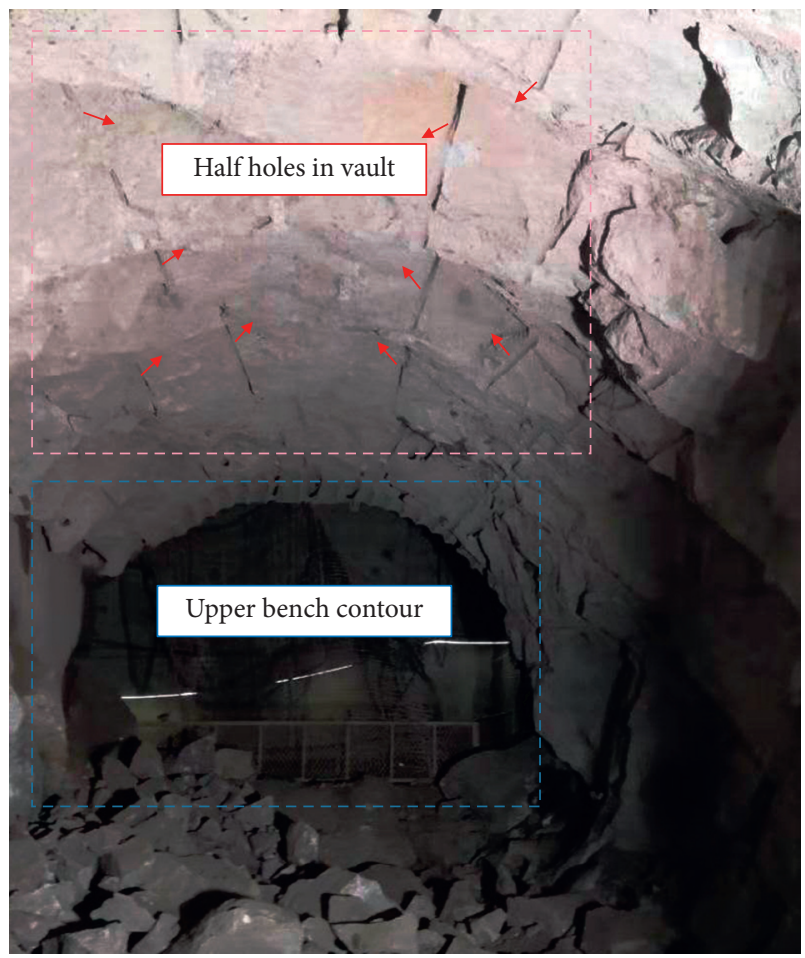

FIGURE 14: Smooth rock fracturing effect.

The average time of each rock fracturing operation was 4.5 hours, and three operation cycles were implemented in one day. The average footage of a single operation of excavation can reach more than $93 \%$. The process from the rock fracturing parameter test to the completion of all excavation operations on the connecting passage lasted 30 days. Compared with other nonexplosive excavation methods, labor productivity was improved, and considerable economic and social benefits were achieved.
3.2. Vibration Monitoring Results and Analysis. Vibration monitoring was conducted throughout the entire process of rock fracturing. The monitoring instruments on the ground and buildings were installed $30.11 \mathrm{~m}$ away from the connecting passage and were not triggered throughout the entire excavation process. Table 2 lists the vibration monitoring results.

The measured maximum vibration velocity at measuring point $\mathrm{K} 1,9.5 \mathrm{~m}$ away from the explosion source in the tunnel, was $1.67 \mathrm{~cm} / \mathrm{s}$. The main frequency of vibration was 166.67 Hz. It was much lower than the vibration speed limit value of $10-20 \mathrm{~cm} / \mathrm{s}$ for the distance specified in Safety Regulations for Blasting. Thus, this rock fracturing method using high-pressure gas expansion causes fewer vibrations for surrounding environment. It is a safe and efficient method to apply to the excavation of hard rock connecting passage within cities.

\subsection{Some Issues on Application}

(1) According to the theoretical calculation and field test results of constant volume reaction heat, the constant volume reaction heat of expansion tube is $2837.88 \mathrm{kj} / \mathrm{kg}$, that of TNT is $4222 \mathrm{~kJ} / \mathrm{kg}$, and that of expansion tube is $67.2 \%$ of TNT, when the aerogenic agent completely reacts with zero oxygen, and the generated water is gaseous. Therefore, the rock fracturing energy of $500 \mathrm{~g}$ gas producer in the expansion tube is equivalent to $336 \mathrm{~g}$ TNT equivalent.

(2) The proposed rock fracturing method mainly relies on high temperature and high pressure gas produced by aerogenic agent in a short time act on rock. Therefore, the effect of rock fracturing is affected by the integrity of rock and the plugging effect of fracturing hole. We suggest that the integrate rock mass should be selected as rock fracturing hole to 


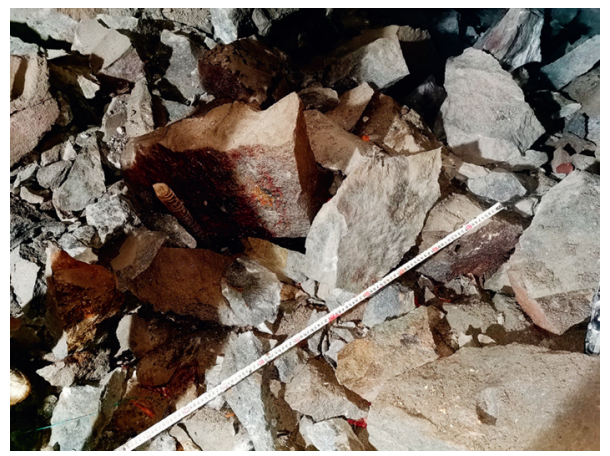

FIGURE 15: Rock fragmentation.

TABLE 2: Results of vibration velocity monitoring.

\begin{tabular}{lccccc}
\hline Location & Number of expansion tubes & Distance $(\mathrm{m})$ & Velocity $(\mathrm{cm} / \mathrm{s})$ & Distance $(\mathrm{m})$ & K2 \\
& 8 & 9.5 & 1.67 & 18.5 & 0.81 \\
Upper bench & 5 & 9.5 & 1.45 & 18.5 & 0.72 \\
Lower bench & & & Velocity $(\mathrm{cm} / \mathrm{s})$ \\
\hline
\end{tabular}

ensure that there is no crack in the rock mass. In addition, the plugging material should have the characteristics of rapid solidification and initial setting strength above $15 \mathrm{MPa}$.

(3) In the aspect of operation safety of high pressure gas expansion method, the process of injecting highpressure gas into expansion tube is a critical process. Because the expansion tube is activated after injecting high-pressure gas, in order to prevent false triggering, during injecting high-pressure gas into the expansion pipe, the high-pressure gas pump should keep a distance of more than $2 \mathrm{~m}$ from the tunnel face, and the workers should not work in front of the tunnel face. When the air pressure in expansion pipe reaches $2.5 \mathrm{MPa}$, the nonblasters will evacuate immediately. After confirming the safety of the site, the blaster will trigger the expansion pipe.

(4) The proposed method is mainly used in the case where the traditional explosive blasting excavation is limited, and only nonexplosive excavation can be used. Compared with other nonexplosive excavation methods, the method has higher rock fracturing efficiency in hard rock with rock strength above $100 \mathrm{MPa}$, so this method is more suitable for hard rock and adjacent engineering construction.

\section{Conclusions}

In this paper, the continuous excavation of hard rock connecting a passage of the Hangzhou subway was used as an example to demonstrate the capabilities of high-pressure gas expansion rock fracturing. The rock fracturing parameters, rock fracturing effects, and vibration response were analyzed using this method. The research results show the following:

(1) The rock fracturing method through high-pressure gas expansion causes fewer environmental disturbances compared to explosive blasting within city limits. Compared with other nonexplosive excavation methods, this method enables continuous excavation for the first time in the case of hard rock connecting passage in subway with the rock strength of over $100 \mathrm{MPa}$. It has brought forth new ideas for rock fracturing within a city.

(2) The parameters of rock fracturing by high-pressure gas expansion are optimized for dense rock and surrounding rock with a rock strength of $100 \mathrm{MPa}$. Hole spacing should be less than $0.5 \mathrm{~m}$, and the minimum resistance line should be less than $0.7 \mathrm{~m}$. With these parameters, excellent smooth rock fracturing effects can be obtained with the rate of half-hole marks reaching over $85 \%$.

(3) The obtained maximum vibration velocity at $9.5 \mathrm{~m}$ away from the rock fracturing area within the tunnel was $1.67 \mathrm{~cm} / \mathrm{s}$, and there was no seismic sense on the ground $30.11 \mathrm{~m}$ away from the rock fracturing area. This indicates that this rock fracturing method through high-pressure gas expansion has unique advantages for hard-rock engineering in complicated surroundings, such as downtown areas, historic preservation sites, and near the area of existing structures. Moreover, its efficient continuous rock fracturing ability is significantly advantageous for hard rock underground engineering in cities. This method has a wide application prospect.

(4) Applying this technology in continuous excavation of hard rock connecting passages can achieve highefficient rock fracturing, microvibration, no slungshot, and no shock wave damage. To demonstrate this method, an excavation scheme for hard rock connecting passage in complicated surroundings was initially formed and has process innovation. This paper can be used for reference in future applications. 


\section{Data Availability}

The data used to support the findings of this study are available from the corresponding author upon request.

\section{Conflicts of Interest}

The authors declare no conflicts of interest.

\section{Acknowledgments}

The research has been supported by the Initiation Fund for postdoctoral research of Central South University, under grant number 228697. The authors would like to thank China Zhejiang Construction Group Dacheng for their assistance with conducting the field experiments.

\section{References}

[1] J. Chen, H. Yu, A. Bobet, and Y. Yuan, "Shaking table tests of transition tunnel connecting TBM and drill-and-blast tunnels," Tunnelling and Underground Space Technology, vol. 96, p. $103197,2020$.

[2] X. Zou, H. Zheng, and Y. Mi, "Performance evaluation of hard rock TBMs considering operational and rock conditions," Shock and Vibration, vol. 2018, Article ID 8798232, 2018.

[3] D. Liu, J. Zhang, Y. Tang, Y. Jian, and C. Cai, "Damage analysis of concrete structure under multi-directional shaped charge blasting using model experiment and ultrasonic testing," Advanced in Civil Engineering, vol. 2021, Article ID 6677041, 2021.

[4] China National Standardization Administration, Safety Regulations for Blasting, China National Standardization Administration, Beijing, China, GB6722-2014, 2014.

[5] S. P. Singh, "Non-Explosive applications of the PCF concept for underground excavation," Tunnelling and Underground Space Technology, vol. 13, no. 3, pp. 305-311, 1998.

[6] S. Wang, X. Li, J. Yao et al., "Experimental investigation of rock breakage by a conical pick and its application to nonexplosive mechanized mining in deep hard rock," International Journal of Rock Mechanics and Mining Sciences, vol. 122, p. 104063, 2019.

[7] L. Wang, B. Guo, and Z. Wang, "A static fracturing technology to enhance the permeability of coalbed: mechanical study," Advances in Civil Engineering, vol. 2019, Article ID 9207145, 2019.

[8] S.-F. Wang, L.-C. Sun, L.-Q. Huang et al., "Non-explosive mining and waste utilization for achieving green mining in underground hard rock mine in China," Transactions of Nonferrous Metals Society of China, vol. 29, no. 9, pp. 1914$1928,2019$.

[9] J. Xu, C. Zhai, P. G. Ranjith et al., "Investigation of nonexplosive expansion material in roof caving field application," International Journal of Rock Mechanics and Mining Sciences, vol. 120, pp. 50-57, 2019.

[10] C. Wei, W. Zhu, S. Chen, and P. Ranjith, "A coupled thermalhydrological-mechanical damage model and its numerical simulations of damage evolution in APSE," Materials, vol. 9, no. 11, pp. 841-860, 2016.

[11] D. Venkatesh, J. D'Entremont, S. Meyer, S. Bane, M. Grubelich, and D. King, "Bipropellant high energy stimulation for oil and gas applications," Journal of Petroleum Science and Engineering, vol. 180, pp. 660-667, 2019.
[12] Y. Bai, L. Sun, and C. Wei, "A coupled gas flow-mechanical damage model and its numerical simulations on high energy gas fracturing," Geofluids, vol. 2020, Article ID 3070371, 2020.

[13] F. Wu, X. Wei, Z. Chen et al., "Numerical simulation and parametric analysis for designing high energy gas fracturing," Journal of Natural Gas Science and Engineering, vol. 53, pp. 218-236, 2018.

[14] N. A. Akcin, "Optimun conditions and results from the application of the air blasting excavation system," Mineral Resources Engineering, vol. 9, no. 3, pp. 323-334, 2000.

[15] N. Vidanovic, S. Ognjanovic, N. Ilincic, N. Ilic, and R. Tokalic, "Application of unconventional methods of underground premises construction in coal mines," Technics Technologies Education Management-Ttem, vol. 6, no. 4, pp. 861-865, 2011.

[16] X. Bai, D. Zhang, S. Zeng, S. Zhang, D. Wang, and F. Wang, "An enhanced coalbed methane recovery technique based on $\mathrm{CO}_{2}$ phase transition jet coal-breaking behavior," Fuel, vol. 265, p. 116912, 2020.

[17] G. Hu, W. He, and M. Sun, "Enhancing coal seam gas using liquid $\mathrm{CO}_{2}$ phase-transition blasting with cross-measure borehole," Journal of Natural Gas Science and Engineering, vol. 60 , pp. $164-173,2018$.

[18] H. Yan, J. Zhang, N. Zhou, and M. Li, "Staged numerical simulations of supercritical $\mathrm{CO}_{2}$ fracturing of coal seams based on the extended finite element method," Journal of Natural Gas Science and Engineering, vol. 65, pp. 275-283, 2019.

[19] B. Ke, K. Zhou, G. Ren, J. Shi, and Y. Zhang, "Positive phase pressure function and pressure attenuation characteristic of a liquid carbon dioxide blasting system," Energies, vol. 12, no. 21, p. 4134, 2019.

[20] H. Peng, D. Liu, F. Chu, and Y. Jian, "Test on high pressure gas expansion rock fragmentation in hard rock tunnel," Rock and Soil Mechanics, vol. 39, pp. 242-248, 2018.

[21] R. Gao, P. Cao, X. Fan, C. Zhang, and T. Y. Liu, "Crack initiation, propagation, and failure characteristics of jointed rock or rock-like specimens: a review," Advances in Civil Engineering, vol. 2019, Article ID 6975751, 2019. 